\section{Recognition Of Prior Learning: Recent Developments and Some Issues}

\section{Colin GunN AND JuLIE McDougall}

\section{Abstract:}

Recognition of prior learning (RPL) policies have been in place overseas for up to two decades. The Education Amendment Act (1990) gave the NZQA the responsibility for developing a national qualifications framework in which "there is a flexible system for the gaining of qualifications, with recognition of competency already achieved." 1993 saw significant developments in the introduction of RPL policies in New Zealand. This paper will review these developments, focusing primarily on New Zealand polytechnics. In particular, it will briefly outline overseas influences on RPL, NZQA policies and actions, and some developments in tertiary institutions in New Zealand. It will define $R P L$, look at some of the guiding principles in applying RPL policies and look at some ways that these policies may be implemented. The paper will conclude by identifying some of the current issues concerning the introduction of RPL to New Zealand. These will include financial, cultural and equity concerns, staff workloads and other considerations.

$\mathrm{R}$ ecognition of prior learning (RPL) policies have been in place overseas for up to two decades and in this time formal and informal arrangements (e.g., credit transfer advanced entry) for the recognition of prior learning have developed in many tertiary institutions in New Zealand.

Recently there has been a move to formalise these arrangements and to ensure that all tertiary institutions have such

\section{Colin Gunn and Julie McDougall}

arrangements in place, a move that has come as a result of the Education Amendment Act 1990. This Act gave the New Zealand Qualifications Authority (NZQA) the responsibility for developing a national qualifications framework in which "there is a flexible system for the gaining of qualifications, with recognition of competency already achieved". (Education Amendment Act 1990, Section 253 (1) (c) (ii))

1993 saw significant developments in the introduction of RPL policies in New Zealand. This paper will focus on New Zealand polytechnics which are beginning to implement the NZQA's national qualifications framework. It will briefly outline influences on the development of RPL particularly in 1993, identify some common principles held about RPL and outline issues facing polytechnics as they develop their own policies.

\section{Influences On The Development Of RPL Policies}

\section{Overseas Influences}

In developing RPL policies and procedures New Zealand has drawn mainly on the American, British and Australian experiences where procedures have been in place for up to 20 years.

Two main approaches are used in the USA. One is the portfolio approach where applicants collate a file or portfolio of evidence to support their claim for academic credit. The second approach is challenge testing where applicants sit a written, oral or practical examination in a subject of their choice. (These terms are discussed below.)

In the United Kingdom the portfolio approach is generally favoured whereas in Australia applicants generally negotiate in an interview situation the amount of credit to be awarded. 


\section{NZQA Policies and Actions}

Due to its responsibility under the Education Amendment Act 1990, the NZQA has been the prime mover in assisting the development of RPL policies and procedures in tertiary institutions. A clear mandate for this development has been indicated by all sections of the community in their responses to the "Designing the Framework" questionnaire (NZQA, 1991a).

Responses to the four questions in the questionnaire on prior learning indicate $86 \%$ support across all sectors of the community. This includes universities, colleges of education, polytechnics, private providers, schools, business and professional groups, unions, local and national government sectors, community groups and individuals.

As a result of this widespread support for RPL, the NZQA, in 1992, funded three research projects:

- an RPL trial using four different assessment methods conducted at Nelson Polytechnic (Gunn \& McDougall, 1992);

- an RPL trial, including the use of group processes conducted by Dale Sheehan of the Christchurch College of Education (Sheehan, 1992); and

- RPL - an exploratory study in a New Zealand University conducted at Victoria University of Wellington (Harré Hindmarsh et al., 1992).

\section{Developments in Tertiary Institutions in New Zealand}

In recognition of the strong interest within tertiary institutions, the Victoria University Centre for Continuing Education ran a training seminar on RPL led by the team from the Broadmeadows TAFE, Melbourne (who co-ordinate RPL training for the whole of Australia). The initial two-day training in May 1992 was followed later in the year with a further two-day session on "Training the Trainers".
In addition to this, following developmental work in 1990 and 1991, Palmerston North College of Education began trialing procedures to match certificated learning of applicants in 1992. This work has been further developed in 1993.

\section{Other developments in 1992}

These included presentations on New Zealand developments in RPL prior to the Broadmeadows training in August a presentation at the ASTE (polytechnic tutor union) conference in August, and a two-day seminar on developing policies in New Zealand polytechnics held in Nelson in November.

\section{Developments in 1993}

At the national level the NZQA continued to play a major role in the promotion of RPL policies. Initiatives included the following.

\section{- NZQA Conference - April 1993}

This three-day conference, organised by the NZQA, drew together representatives from a wide range of education providers and industry. Prior to the conference proper two two-day workshops on RPL ran concurrently. Norman Evans of the Learning for Experience Trust (LET) in London presented one workshop. Margaret Brownlie-Williams from the Scottish Vocational Educational Council (Scotvec) ran the other. The conference itself raised many issues concerning the recognition of prior learning (see below). Conference papers were subsequently published (NZQA, 1993a).

- NZQA policy on RPL finalised August 1993

A draft NZQA policy on RPL was distributed at the April Conference and was finalised and distributed to education providers in August (NZQA, 1993b). It lays out in very broad terms the approach that Framework providers must have to RPL. 
A major concern of the writers is the apparent softening of the NZQA approach to RPL during the early part of 1993. Throughout 1992 it was clear that the implementation of RPL procedures was mandatory for organisations wishing to offer Framework units. When the draft NZQA policy on RPL was released at the April conference it became apparent that providers could choose whether they wished to implement RPL procedures. What has remained mandatory is a commitment to RPL. This can be simply demonstrated through a written policy statement.

If organisations do not choose to implement RPL, the NZQA may have difficulty in meeting its statutory obligation under the Education Amendment Act 1990.

- Booklet on RPL published October 1993

The booklet "The Recognition of Prior Learning" (NZQA, 1993c) spells out in more detail RPL principles, the criteria for provider and National Standards Body accreditation to implement RPL, and a good practice model.

- NZQA support for writing up unit standards for RPL throughout 1993

During 1993 the NZQA contracted Dave Hornblow of the Open Polytechnic of New Zealand to assist in the writing of unit standards on RPL. Five units are being drafted: understanding RPL - a basic overview, plus separate units targeted at the following: candidates, facilitators, assessors and managers.

- RPL Training for Trainers - October 1993

To assist providers with the implementation of RPL, the NZQA is providing RPL training for different groups including polytechnics, private providers and industry training organisations. Organisations were asked to select one person to attend three days of RPL training held in various centres around New Zealand. This person becomes the RPL trainer in their organisation and will become part of an informal network of trainers through the country.

At the local level, polytechnics have responded with considerable speed. In a short survey conducted by the authors in November 1993 and responded to by 24 of the 25 New Zealand polytechnics, just over half (13) are already awarding credit for prior learning in at least one faculty/ department. Only one indicated that they had yet to attempt policy development (and two did not answer this section).

\section{Some Common Principles}

It is not possible here to give anything but the briefest of outlines. For an overview see Gunn (1992) and for more detail see Gunn \& McDougall (1992).

Gunn \& McDougall (1992) recommended that New Zealand polytechnics develop their own policies for the granting of RPL. This recommendation reflected both recent movements to strengthen the autonomy of polytechnics and the range of polytechnics in New Zealand (the largest exceeding the size of some universities and the smallest being smaller than many polytechnic faculties and departments).

\section{The Guiding Principles of RPL}

A review of the New Zealand literature indicates much common ground when it comes to statements of principles. It is possible that this results from the leadership role provided by the NZQA, from Broadmeadows TAFE workshops run in New Zealand in 1991-92 and by the NZQA commissioned research projects (McDougall \& Gunn, 1992; Harré Hindmarsh et al., 1992 and Sheehan, 1992).

For convenience the principles may be summarised as below: 


\section{General Principles}

These include statements acknowledging:

- that if the student can satisfactorily demonstrate prior learning then RPL credit should be awarded;

- Tino Rangatiratanga - the tangata whenua have the right to determine how their prior learning will be assessed and recognised; and

- the need to ensure ease of access, fairness, flexibility, institutional commitment, openness of systems and support for applicants.

\section{Specific Principles}

These include the following statements:

- specific learning outcomes are the focus, not general life experiences; when or where learning takes place is not an issue; if currency of learning is important then this will be addressed in the learning outcomes;

- assessments should be made by competent staff meeting standard assessment criteria;

- it is the students' responsibility to collect the evidence of their prior learning;

- credit awarded through an RPL process should not be distinguished from credit awarded in other ways; and

- RPL policies should be reviewed regularly and evaluation research conducted to monitor standards.

\section{Methods Of Proving RPL}

The Gunn \& McDougall (1993) report outlined, on the NZQA's recommendation, four broad methods of demonstrating prior learning. They were:
Attestation others speaking on behalf of the student'slearning;

Challenge demonstrating through an examination - written, oral, practical, etc;

Credit Transfer recognition of non-framework course learning;

Portfolio a collection of materials e.g., letters of support, photographs, models, written statements.

The November 1993 survey conducted by the writers indicated that 16 of the 24 polytechnics are including all four of these methods as options available to students and that a further five are using at least two of the four options. A fifth method, the interview method, is the basis of the Broadmeadow TAFE model but it is also central to most of the four methods listed above and, as described in the interface between Phases 1 and 2, discussed below.

\section{Steps In Processing An RPL Application}

The Gunn \& McDougall (1992) recommendations also allowed for different procedures to develop within a credit awarding institution. Underpinning this recommendation was also the acknowledgment of academic autonomy that New Zealand universities have maintained. Although variations are likely, it is probable that the applicant for credit will fall into three phases. These are:

\section{Phase 1 Request and Evidence Collection}

This is substantially the responsibility of the student who, with advice and support from the credit awarding body, accumulates and presents the evidence of their prior learning, relating it to the specific learning outcomes of the unit(s) for which credit is being sought. 


\section{Phase 2 Assessment and Decision}

This phase is substantially the responsibility of the credit awarding body. The student's evidence/submission is assessed and a decision made.

Note: In practice, Phases 1 and 2 may merge. For example, in a demonstration or attestation (see below) the presentation of evidence and the assessment may take place at the same time.

\section{Phase 3 Appeal}

This phase covers the processes used should the applicant wish to dispute the outcome of Phase 2. This phase is expected to be rarely used.

\section{Current Issues In RPL Policy Development}

In the survey of polytechnics conducted by the authors in November 1993, 13 issues were presented. These issues were selected after an examination of the Conference Papers (NZQA: 1993a) presented at the NZQA Conference on the Recognition of Prior Learning and the National Qualifications Framework 21-23 April 1993. Respondents to the survey were asked to identify the seriousness of each issue. While the authors recognise the limitation of this quick survey they were interested in both the outcomes and the differences between different sized polytechnics.

Brief questionnaires on RPL courses were mailed out to Academic Managers at all twenty-five New Zealand polytechnics early in November. Twenty-four responses were received - a return rate of $96 \%$. Respondees identified their polytechnic's size as follows:

$\begin{array}{lr}\text { Small } & 6 \\ \text { Medium } & 11 \\ \text { Large } & 7\end{array}$

\section{Colin Gunn and Julie McDougall}

While workload was the most serious concern of the small polytechnics, it did not rank in the top five concerns for middle sized polytechnics. For large and middle sized polytechnics alike, one of the top concerns was financing RPL.

The 13 issues canvassed when arranged in order of seriousness, were as follows:

1. The difficulty of financing RPL is such that the introduction of RPL policies is being seriously impeded.

2. While RPL has the potential to redress some equity concerns the procedural/administrative requirements may well prevent this from happening.

3. For staff, RPL will mean a substantial increase in workload without a corresponding adjustment in time or money.

4. The introduction of the NZQA Framework has raised some debate on how specific learning outcomes can and should be. RPL procedures (existing or proposed) increase the level of seriousness of this concern.

5. There is an urgent need for the development of national RPL guidelines, promotional materials and handbooks.

6. The cost to students of RPL (in time and fees) is likely to make it a little used option.

7. Students will not exercise RPL options because of uncertainty over entitlements to Study Right, Student Loans or Student Allowances.

8. It is difficult to develop RPL assessment procedures that meet the same rigour as procedures for awarding credit in the conventional manner.

9. There has been insufficient attention paid to national training opportunities in RPL matters. 
10. The development and administration of RPL policies has involved a balance between central control and local autonomy. The scales have been tipped in favour of central control.

11. Again in comparison with NZQA Framework Units taught in the conventional manner, RPL procedures will make it more difficult to acknowledge cultural learning.

12. RPL policies will result in the loss of academic autonomy for teaching institutions.

13. RPL has the potential to reduce teaching to an assessment only service.

Space does not allow discussion on all 13 issues. Below are some comments on the first five. A fuller discussion may be found in an article by Phil Ker (1992) written for the Association of Staff in Tertiary Education News. It is one of the earliest and remains one of the best coverages of RPL issues.

\section{Financial Issues}

The financing of RPL is clearly a major area of concern. Administrators and students alike have a direct interest and it is obviously difficult to develop policies in the absence of funding decisions. A plenary session of the NZQA April 1993 Conference supported the following resolution.

Participants attending the RPL Conference sponsored by NZQA call upon the CEO of NZQA to seek an urgent meeting with the Ministers of Education, Labour and Employment to set up a task force to investigate the resourcing and funding of the implementation of RPL. The task force to address issues including the following:
1. resource requirements to provide an RPL advisory and assessment service;

2. costs associated with assessment in specific contexts;

3. alternative funding regimes;

4. the impact of each funding regime on educational access and equity;

5. the impact of each funding regime on Study Right, Student Loans, Student Allowance and Training Benefits;

6. the impact of each funding regime on viability of courses, taking into account different forms of provision and awards.

These concerns remain substantially unaddressed and the future of RPL policies in the next few years might well depend on whether or not solutions are found. Some of the key issues within this large one are reviewed below.

From the student's or applicant's perspective it is critical that the cost of applying for RPL be kept as low as possible. This is important in allowing access to education for all groups in the community whatever their financial means. Students will be concerned to see that the cost of gaining credit is no more than the normal course fee and many may expect it to be considerably less.

There are also issues for the applicant that relate to retaining their eligibility for Student Allowances and Student Loans. If having RPL granted means the applicant is no longer undertaking a full-time course, or if it has an impact on their usage of their Study Right then they need to be aware of this and of the implications. 
From the education provider's working perspective within the current Equivalent Full Time Student (EFTS) funding framework, RPL also raises many issues. One of these is whether a provider will be funded for the EFTS value of the credits awarded for prior learning. This is of particular concern for year long courses where an applicant may gain credit for the first half of the course and only attend the second half - leaving an empty seat in the class (or 0.5 EFTS).

Another issue relates to the possible criteria used for costing RPL. Cretney (1993) has considered a number of options. The writers believe the following deserve more discussion.

For integrated programmes (i.e., a succession of integrated units) with an overall EFTS rating the following could apply:

- Study Right usage could be rebated for the period of any RPL exemption gained and the institution would retain a full EFTS claim for the student

\section{and EITHER}

- Student fees could be rebated on a pro rata basis related to course proportion for those sections exempted through RPL, and

- Students could be charged for the actual costs of RPL assessment

OR

- Students could pay normal course fees, and

- Students could not be charged for RPL assessment.

Hopefully the student would pay the lesser fee as calculated for each of these options.

For modular programmes where module or unit exemption is possible the following could apply:
- Study Right would not be used for modules exempted through RPL.

- No course fees would be payable for modules exempted through RPL.

- Students could be charged for the actual costs of RPL assessment.

- The institution would not claim EFTS for the module involved.

If RPL can be EFTS funded this will greatly facilitate the implementation of RPL by providers. If it is not, then ways of recovering the costs incurred will need to be found. In establishing these mechanisms it is important that the principles of RPL are not forgotten.

It appears at present that the Ministry of Education is not recognising the potential impact of RPL on EFTS funded institutions. In information received at Nelson Polytechnic from the Ministry dated 22 October 1993, tucked away on page 9 under the heading "Competency Assessment or Learning Support" is the statement:

Institutions may not claim any portion of the EFTS places exempted by virtue of recognition of prior learning.

Further dialogue is clearly needed at a national level.

\section{Equity Concerns}

In theory RPL holds great promise for those who have developed expertise outside of formal instruction. There is a concern, however, that systems developed by academic organisations, and administered by those who flourish within them, may not adequately meet the challenges of cultural gender and ability sensitivity. 
The authors' November 1993 survey identified two issues in this area. One noted that while RPL has the potential to redress some equity concerns, administrative requirements could well prevent this from happening. The second asked whether, in comparison with the NZQA units taught in the conventional manner, RPL procedures would make it more difficult to acknowledge cultural learning. The results were interesting. There was clear concern that the administrative requirements might weaken the potential to redress equity concerns, but there was low concern from the respondents that RPL procedures would acknowledge cultural learning difficulties.

The NZQA 1993 Conference included a number of informal discussion groups, two of which addressed these issues. The Conference notes recorded the following:

\section{Informal Discussion Topics: $\quad$ Recognising Different \\ Perspectives, Values, \\ Cultures and Histories}

\section{Issues:}

1 that RPL will advantage the advantaged;

2 that RPL is influenced by Industry/Employer needs;

3 that RPL was seen originally as potentially advantageous to women, Maori, people with disabilities and others but may not be;

4 that the power and control remains with the same group in this society;

5 that Maori learning should not have to fit a non-Maori framework;

6 that some models of Maori RPL have been captured by nonMaori and misused, e.g., Te Ataakura, Kohanga Reo;
7 that creativity should be encouraged, but will threaten the structures;

8 that other government policies will and do impact on RPL and will crunch RPL unless creative co-ordination occurs;

9 that standards should be inclusive rather than exclusive;

10 that there is an essential need for non formal, flexible methods of RPL (e.g., attestation).

\section{Informal Discussion Topic: Maori Issues}

Note: The Informal Topic Discussion group of Maori Issues composed the following recommendation to NZQA. It was put to the Conference participants on the final day of the Conference and gained unanimous support.

"There must be some directive from government through their contracts with post-compulsory education and training providers and industry training organisations to establish a process or system of ensuring that Maori at national and local levels are part of the planning of attestation development, assessment and monitoring of RPL.

In this way government will be giving a clear signal of their commitment to this process. This will also ensure that the postcompulsory education training providers and industry training organisations are not left in a position of deciding whether they wish to participate or not.

for RPL to be effective, Maori people must be active participants in the process without question or debate."

It remains to be seen whether government and the various polytechnics rise to meet these challenges. 


\section{Staff Workloads}

Discussion at a 1992 Association of Staff in Tertiary Education (ASTE) Conference workshop led by the writers and at the 1993 NZQA Conference made it clear that staff fear that they will be expected to pick up the additional responsibilities of administrating assessing RPL applications without adequate compensation in time or money.

The authors' November 1993 survey indicated that these fears remain. Informal feedback from staff (as received by the writers in workshops they have altered or led) indicates that much of the early "pilot" work in providing a RPL service has relied heavily upon staff goodwill. It is unlikely, as RPL policies are formally adopted and its usage increases, that this can be sustained at the required levels. Clearly this issue is inseparably linked to that of the overall funding of RPL policies and like those issues it may have a powerful effect on the speed with which RPL develops.

\section{How Specific Can Learning Outcomes Be?}

This debate is really a debate about the National Qualifications Framework and the assumptions, beliefs and facts that underpin it. With the NZQA focus on the identification of specific learning outcomes in their National Qualifications Framework it became inevitable that these were part of the RPL assessment policy (See Gunn \& McDougall, 1992).

In the NZQA survey (1991a) 83\% support was received across all sectors in response to the question "Do the advantages of the unit of learning approach outweigh its disadvantages?"

However support was only $30 \%$ and $34 \%$ respectively for the questions, "Is competence based/achievement based assessment suitable for all areas of learning?" Perhaps as more units are written, ways will be found to address these issues.

\section{The Need for Guidelines and Promotional Materials}

For many polytechnics RPL is a very recent concept and it has come at the same time as many other changes and administrative requirements. It is not surprising that the polytechnics would welcome assistance in the development of RPL guidelines, handbooks and of promotional materials. It is far from clear that these requests will bear fruit. Gunn \& McDougall (1992) made a tentative but incomplete start on handbooks/guides. At this point, it appears that the initiative will rest with each polytechnic, possibly aided by the exchange of materials through informal networks.

\section{Conclusion}

1993 has been a significant year in the development of RPL policies. For many, ideas raised for the first time in 1992 have been acknowledge and developed. Within New Zealand polytechnics there is wide acceptance of the concept of RPL and some strong similarities in the way RPL policies are being implemented and the issues being raised. As each polytechnic refines policies to meet its own conditions, one might expect the acceptance of the RPL concept to strengthen, but that the similarities might diminish due to the diversity of the communities that polytechnics cater for. Likewise a number of common issues exist. As policies develop and particularly as funding mechanisms become clear some of these issues may diminish.

Tertiary framework providers (such as polytechnics) have responded positively to RPL. There also appears to be a core group of administrators and staff within these organisations who are keen to promote RPL and who take up with relish the opportunities provided by the NZQA initiative. But unless some of the key issues discussed above are resolved, this goodwill could well dissipate. 
It is as yet unclear how non-framework providers (e.g., universities) will respond. There is a possibility that two distinct systems might emerge (albeit with some common elements). If this is so it will be important that the increasing number of students moving from one to the other are not disadvantaged.

\section{References}

Cretney, J. "Unpublished brief paper on RPL costing options", Nelson: Nelson Polytechnic, 1993.

Griffin, H. and Brooking, K. "Assessment of Prior Learning Report Number Two" prepared for the Palmerston North College of Education, 1991.

Gunn, C. "Recognition of Prior Learning. What is it? What does it involve?", in Journal of Adult Learning, Vol. 20, No..2, October 1992, pp. 51-64)

Gunn, C.. and McDougall, J. "Recognition of Prior Learning-Guidelines with Policy Development", Nelson: Nelson Polytechnic, October 1992.

Harré Hindmarsh, J. et al. "Recognition of Prior Learning : An Exploratory Study in a NZ University", Wellington: NZQA and Victoria University of Wellington, 1992.

Ker, P. "Recognition of Prior Learning. Can we deliver the Promise?" ASTE News, No. 3, Wellington: Association of Staff in Tertiary Education, 1992.

NZQA, "Recognition of Prior Learning: A Background Paper", Wellington: New Zealand Qualifications Authority, 1991a.

NZQA, “Developing the National Qualifications Framework - a report to the Board", Wellington: New Zealand Qualifications Authority, 1991b.

NZQA, "Recognition of Prior Learning and the National Qualifications Framework" Conference, April, Wellington: New Zealand Qualifications Authority, 1993a.
NZQA, "Policy on the Recognition of Prior Learning", Wellington: New Zealand Qualifications Authority, 1993b.

NZQA, "The Recognition of Prior Learning" Practical Information Booklet, Wellington: New Zealand Qualifications Authority, 1993c.

NZQA, Policy on the Recognition of Prior Learning, Ker, P, ASTE Newsletter.

Sheehan, D. "Recognition of Prior Learning Trial: Report to New Zealand Qualifications Authority", Christchurch: Christchurch College of Education, 1992.

\section{The authors}

Cohn Gunn and Julie McDougall are employed by Nelson polytechnic. They were the researchers for that polytechnic's contract with NZQA to develop guidelines on the development of RPL policies in New Zealand polytechnics. They have also conducted a number of workshops and presented papers on this topic. 